\title{
OBSERVATIONS ON THE SHOALING BEHAVIOUR OF COD (GADUS CALLARIAS) IN DEEP WATER RELATIVE TO DAYLIGHT
}

\author{
By G. H. Ellis
}

[Kelvin and Hughes Ltd]

\section{(Plates I and II)}

It is well known that vision is the main physical factor governing the formation and maintenance of fish shoals, and that, in general, shoals break up when the light intensity falls below a certain level. Breder (I929, I942), Newman (I876), Parr (I927, I93I), and others, have shown this by laboratory experiment.

During a commercial fishing voyage to the Barents Sea it became possible, by means of a recording echo-sounder, to study the shoaling behaviour of cod in deep water relative to light intensity. The observations were made aboard the Hull trawler Lancella whilst fishing in a depth of I Io fathoms at Skolpen Bank in September 1955. For this a Kelvin and Hughes recording echosounder type MS. 24J was used, the depth range across the chart being 55 fathoms. The scale was phased so that the region between 80 and 135 fathoms deep was displayed.

The trawler was, for the period of I9 h, towing over substantially the same ground on consecutive trawling tows, position and direction of tow being maintained by the use of radar equipment in conjunction with two anchored dan buoys. The duration of each tow was approximately $2 \mathrm{~h}$. The fishing gear used was a standard deep sea trawl, and the towing speed of the vessel was 4 knots.

The charts (Pls. I, II) show the results obtained on seven consecutive trawling tows made between I3.IO G.M.T. on I7 September I955, and 08.I5 G.M.T. on I8 September 1955, for which particulars are given in Table I. It will be noticed that all recorded echoes have serrated edges, and that there is occasional ' missing' and 'lining' on the charts. These effects are caused by the vertical movement of the vessel due to heavy swell which persisted throughout the tows. All fish caught whilst these charts were recorded were cod, the length of which lay between 40 and $90 \mathrm{~cm}$. From the catches it is assumed that the recorded fish traces were due to cod of sizes within this range.

The charts show clearly that the cod were mainly in compact shoals during daylight hours, and that during darkness they were distributed fairly evenly over the whole area of the tow. The process of dispersal started just before 


\section{Table I. Description of Charts}

\begin{tabular}{|c|c|c|c|}
\hline Pls. I, II & Times of tow, G.M.T. & $\begin{array}{l}\text { Catch per } \\
\text { hour } \\
\text { (baskets) }\end{array}$ & Description of traces \\
\hline Chart $(a)$ & I3.10-I 4.55 h, I7. ix. 55 & 70 & $\begin{array}{l}\text { Dense 'Thumbprint' record- } \\
\text { ings throughout the whole } \\
\text { tow. Few crescent traces due } \\
\text { to single fish }\end{array}$ \\
\hline Chart $(b)$ & I $5.45-$ I 7.45 h, I7. ix. 55 & 60 & $\begin{array}{l}\text { Fairly dense traces at the } \\
\text { beginning of the recording, } \\
\text { thinning out into less distinct } \\
\text { single crescent echoes }\end{array}$ \\
\hline Chart $(c)$ & I $8.30-20.30$ h, I7. ix. 55 & 75 & $\begin{array}{l}\text { Single crescent echoes through- } \\
\text { out the tow }\end{array}$ \\
\hline Chart $(d)$ & 21.10-23.30 h, I7. ix. 55 & 50 & As $(c)$ \\
\hline Chart (e) & $00.10-02.30 \mathrm{~h}, \mathrm{I} 8$. ix. 55 & 50 & As $(c)$ and $(d)$ \\
\hline Chart $(f)$ & $04.00-06.00$ h, I8. ix. 55 & 35 & $\begin{array}{l}\text { Dense 'Thumbprint' traces } \\
\text { throughout recording with } \\
\text { some single crescents }\end{array}$ \\
\hline Chart $(g)$ & $06.25-08.15$ h, I8. ix. 55 & 35 & As recording $(f)$ \\
\hline
\end{tabular}

Weather and sea

Overcast, fairly heavy swell

No moon, overcast,
fairly heavy swell

No moon, overcast, fairly heavy swell
As (c)
As (c) and (d)
Hazy, fairly heavy

Bright and clear, fairly heavy swell
Remarks

Tow made in daylight ending shortly before sunset. The fish are mainly in discrete shoals forming a composite target. Average height of fish from sea-bed Io fm

Tow made during and after sunset. The shoals have split up at sunset and the fish have dispersed evenly over the whole of the tow between the sea-bed and $30 \mathrm{fm}$ above

Tow made during darkness.

The fish are spread out over the whole tow area between the sea-bed and $30 \mathrm{fm}$ above

As (c)

As $(c)$ and $(d)$

Tow made after sunrise. The fish have re-formed into compact shoals; average height of fish from sea-bed Io fm

Tow made in daylight. The fish are mainly in discrete shoals as on the previous daylight recordings (Charts $(a)$ and $(f))$. Average height of fish from sea-bed io fm 


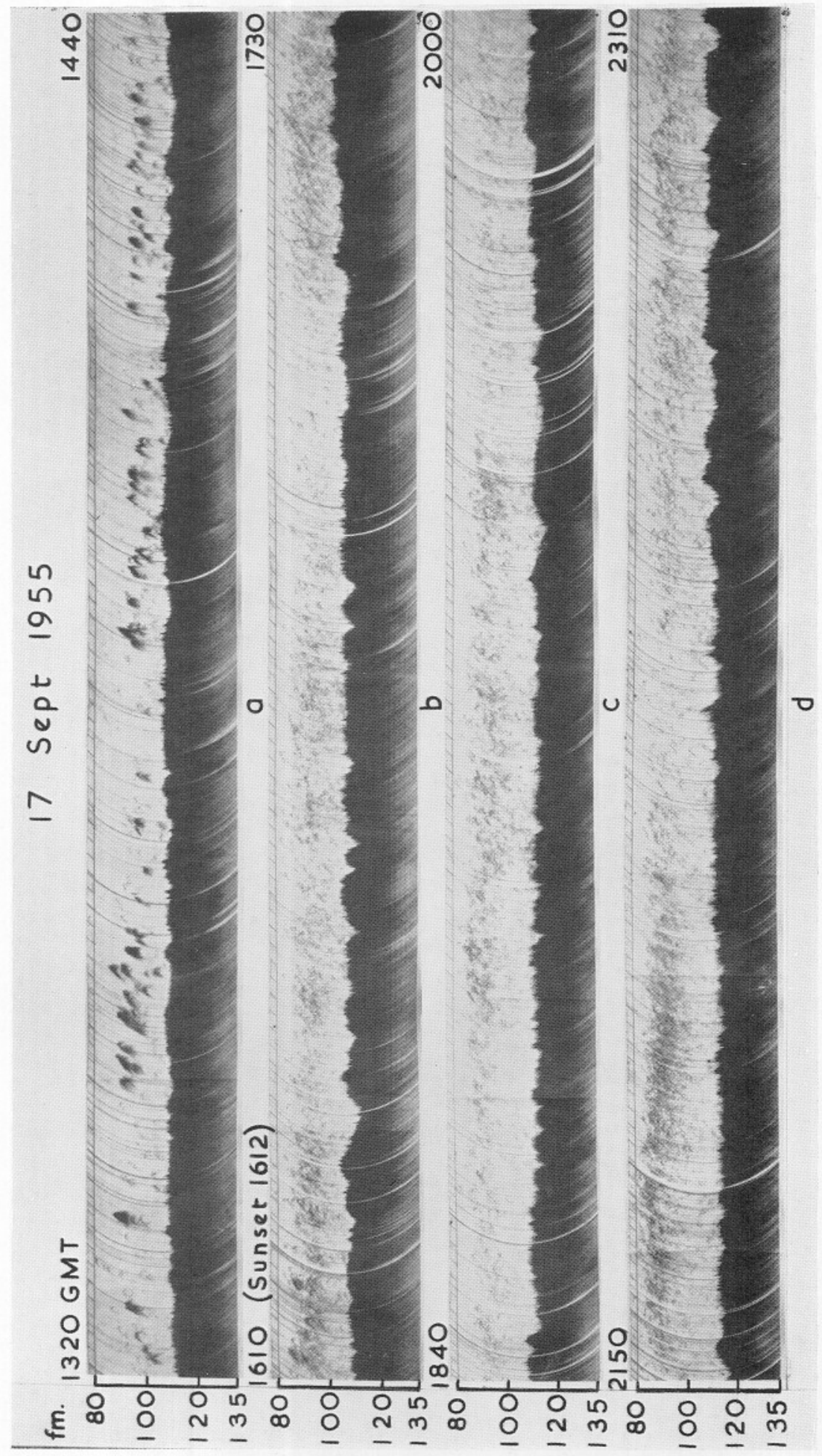

(Facing p. 4I6) 


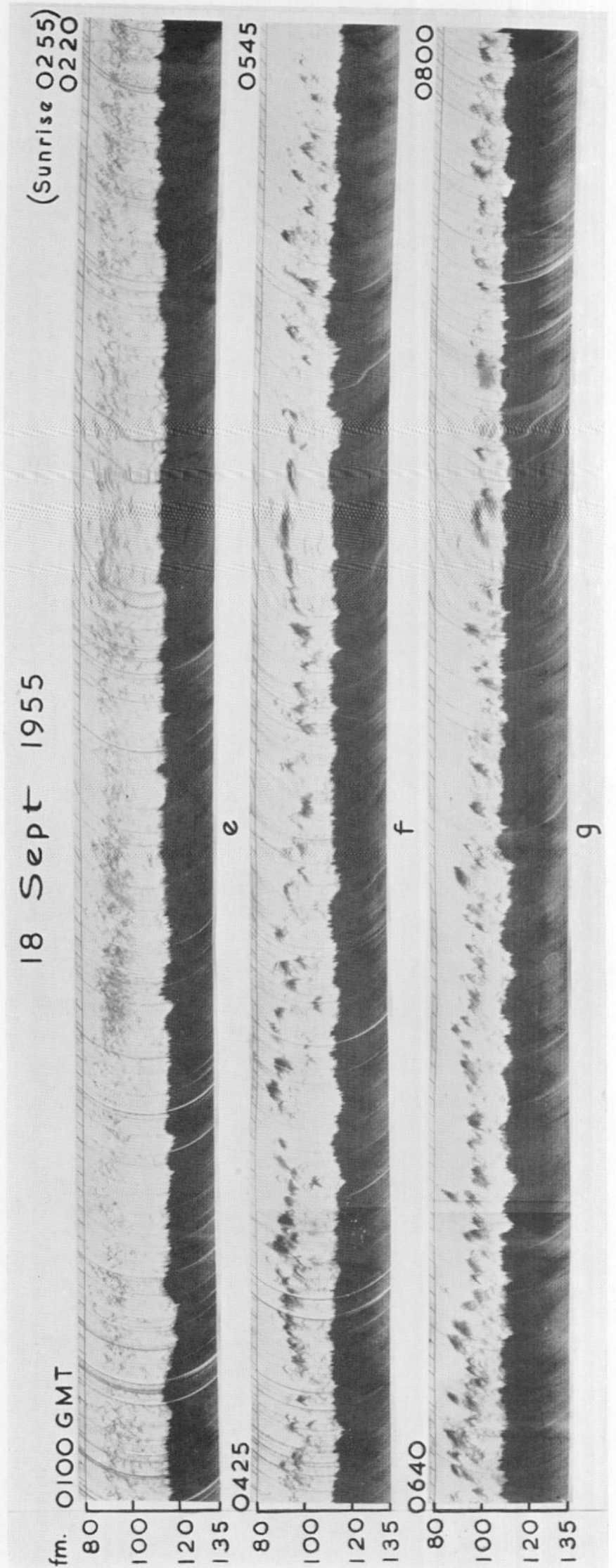


the sunset at I6.I2 G.M.T., presumably when the light intensity fell below the threshold of vision of the cod. Conversely, there is evidence to show that the re-forming of the shoals took place at sunrise (02.55 G.M.T.).

The average height of the fish above the sea-bed remained at about the same level (IO-I5 fm) irrespective of the formation of the fish. Unlike sprats and herring, which have been shown by Richardson (I952) to exhibit diurnal vertical migration, the cod maintained the same average level throughout daylight and darkness, although the maximum height above the sea-bed was greatest in darkness.

The maximum possible vertical movement of the fish on dispersal at night, i.e. $30 \mathrm{fm}$ (about $25 \%$ change in level), was well within the theoretical limits imposed by the swim-bladder as deduced by Jones (I952).

The catches did not vary significantly with the change in formation of the fish.

\section{SUMMARY}

During a commercial fishing voyage to the Barents Sea continuous observations were made on the shoaling behaviour of cod in deep water over a period of $19 \mathrm{~h}$.

The cod were studied by the use of a Kelvin and Hughes MS. 24J recording echo-sounder.

Compact cod shoals recorded in $100 \mathrm{fm}$ during daylight dispersed at sunset and re-formed at sunrise.

The maximum possible vertical movement of the fish during observation was $30 \mathrm{fm}$.

The catches did not vary significantly with the formation of the cod.

\section{REFERENCES}

BREDER, C. M., JR., I929. Certain effects in the habits of schooling fishes, as based on the observation of Jenkinsia. Amer. Mus. Novit., Vol. 382, pp. I-5.

1942. Social and respiratory behaviour of large tarpon. Zoologica, N.Y., Vol. 27, pp. I-4.

HARDEN JONES, F. R., I952. The swim bladder and the vertical movements of teleostean fishes. II. The restriction to rapid and slow movements. F. exp. Biol., Vol. 29, pp. 94-I09.

Newman, E., I876. Mr Saville Kent's lecture, at the Society of Arts, on 'The aquarium: construction and management'. Zoologist, Ser. 2, Vol. Ir, pp. 4853-8.

PARR, A. E., I927. A contribution to the theoretical analysis of the schooling behaviour of fishes. Occ. Pap. Bingham oceanogr. Coll., Vol. I, pp. I-32.

- 193I. Sex dimorphism and schooling behaviour among fishes. Amer. Nat., Vol. 65, pp. 173-80.

RICHARDSON, I. D., I952. Some reactions of pelagic fish in light as recorded by echo sounding. Fish invest., Lond., Ser. 2, Vol. 18, p. I. 